\title{
Gastric Cancer: A Well-Behaved Helicobacter pylori-Related Disease?
}

\author{
Robert M. Genta
}

Published online: 4 February 2011

(C) Springer Science+Business Media, LLC (Outside the USA) 2011

Interest in birth cohorts as a means to investigate gastric disease stemmed from a 1962 paper published in The Lancet by Mervyn Susser and Zena Stein, a South African couple who had recently immigrated to Manchester, England [1]. By a series of fortuitous circumstances Mervyn was invited to contribute a review on the epidemiology of peptic ulcer for a symposium to be published in The Practitioner, a monthly journal distributed free to UK general practitioners for 140 years. In their own words, Susser and Stein had "at most a half-dozen joint or separate publications, no track record in the subject of peptic ulcer, and no knowledge of the disease, that was a rarity in the Black South Africans among whom [they] had worked" [2]. While preparing the review Susser and Stein explored epidemiologic changes over time and experimented with different ways of plotting mortality data, in an attempt to determine whether mortality from peptic ulcer was constantly rising, as it was widely believed at the time.

Using birth cohort analysis, a method that follows the incidence of a condition (in this case mortality from peptic ulcer) in an aggregate of individuals having a significant event in their life histories in common (in this case the year of birth), Susser and Stein detected a pattern of waxing for the late 19th century births and then waning through the births of the 20th century. Only briefly mentioned in the review for The Practitioner, their analysis was later expanded for the seminal article "Civilization and Peptic Ulcer" [1]. At that time, stress related to industrialization, urbanization, and the deprivations and air raids Britain endured during World War II seemed to offer a fitting explanation for the mortality

R. M. Genta $(\bowtie)$

Caris Research Institute, Caris Life Sciences, 6655 North MacArthur Blvd, Irving 75039, Texas

e-mail: robert.genta@utsouthwestern.edu trends observed. The paper, which was incorrectly assumed to provide evidence for the psychosomatic nature of peptic ulcer, became widely popular.

The discovery-or, as purists would have it-the re-discovery of Helicobacter pylori by Marshall and Warren in 1984 radically changed our concepts of ulcer disease and gastric cancer [3]. Enter Amnon Sonnenberg. From 1984 on he applied birth cohort analysis to explore time trends in the mortality of a variety of gastrointestinal diseases [4-7], but it was not until the early 1990s that the crucial influence of H. pylori infection became apparent [8, 9].

In 2002, The International Journal of Epidemiology dedicated an issue to a Festschrift in honor of Mervyn Susser and Zena Stein, now both professors emeriti at the Mailman School of Public Health at Columbia University in New York. In a commentary entitled "The unresolved mystery of birth-cohort phenomena in gastroenterology", Sonnenberg et al. wrote that "gastric cancer is actually the only disease whose trends vary in the time-dependent fashion one would expect from a well-behaved $H$. pylorirelated disease." In a new study published in this issue of Digestive Diseases and Sciences [10], Sonnenberg follows further the time trends of gastric cancer and peptic ulcer in six European countries for the past 56-85 years. This analysis, as it is often the case, answers some questions while generating new enigmas: what happened in Europe that caused gastric cancer mortality to rise in generations born during the first half of the 19th century, with a peak between 1870 and 1890? What caused its subsequent decline? Why do gastric and duodenal ulcers show similar time trends, but delayed by about 30 years? Do these findings still fit with the good behavior expected of a Helicobacter pylori-related disease? Figure 1 is a highly simplified attempt to provide a graphic interpretation of what may have happened. 


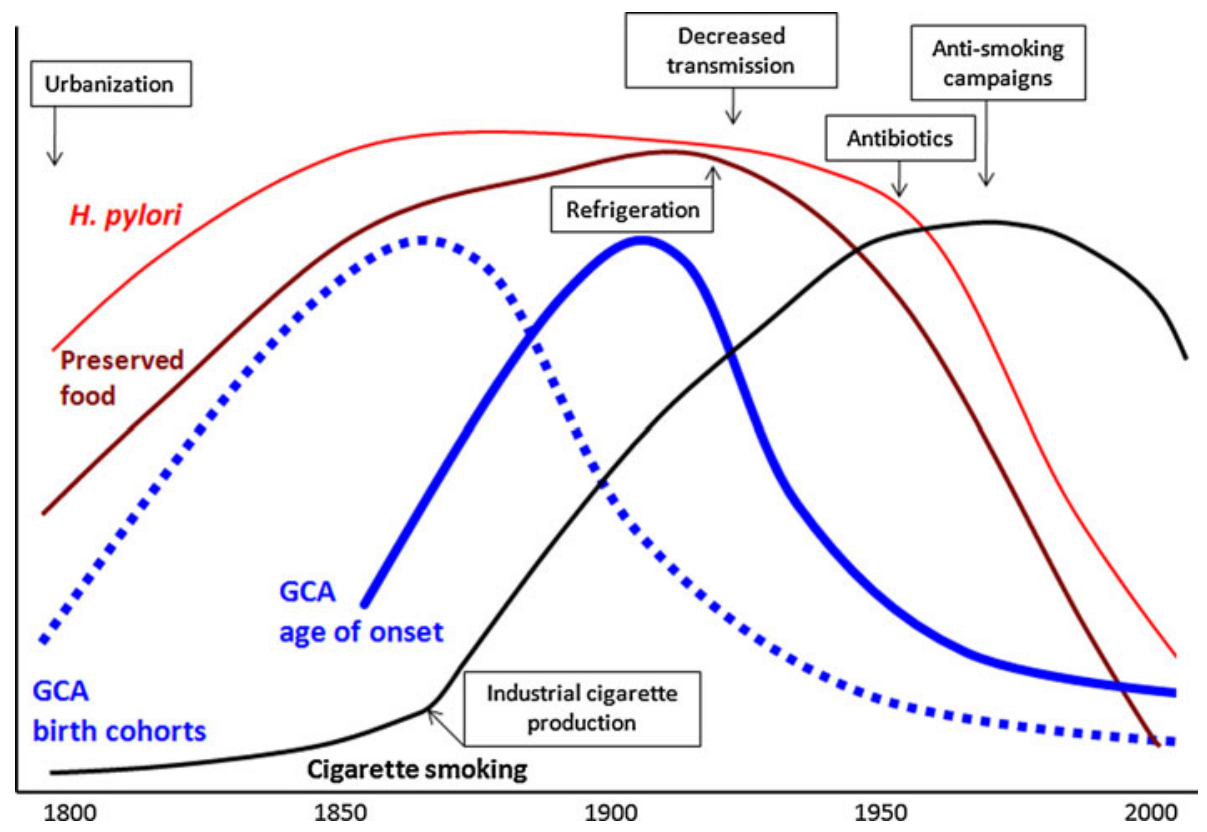

Fig. 1 A cohort-mortality ratio curve for gastric cancer (GCA birth cohorts) inferred from Sonnenberg's amalgamated data [10] is represented by the dotted blue line. Assuming that gastric cancer arises most commonly between the ages of 40 and 60 years, the age of onset would look like the curve depicted by the solid blue line (GCA age of onset). H. pylori (prevalence trends indicated by the red line) causes atrophic metaplastic lesions that make the gastric mucosa more susceptible to other carcinogenic factors, such as salt, nitrites, and nitrosamines (all represented by the brown line; preserved food). Cigarette smoking (black line) appears to have gastric carcinogenic effect mostly, if not exclusively, in $H$. pylori-infected subjects. This largely hypothetical scheme illustrates how the convergence and subsequent divergence of three factors might partially explain the time trends for gastric cancer shown by Sonnenberg in some European countries

major colonizer of the human stomach. More virulent genotypes, until then perhaps relegated to small isolated groups, may have found their way into the newly urbanized populace to become the dominant infecting strains. With more virulent infections there developed chronic gastritis, atrophy and metaplasia (what we have called the "third world stomach"), preparing the background for gastric cancer. However, $H$. pylori infection alone is not sufficient to cause gastric cancer. Other factors also must have been operative.

Urbanization altered the dynamics of food availability. Dairy products, produce, and fruits, readily available to rural dwellers, effectively disappeared from the diet of the urbanized poor. Poultry, fish, venison, and other fresh meats, accessible in the countryside to anyone who could keep a few chickens and goats in their home and to those who could fish or hunt, needed to be preserved for transport to the city. Preservation of meat and fish was achieved by smoking and by the addition of salt (brine) and nitrites. Thus, the new diet of city dwellers suffered a dramatic decrease in vitamin intake coupled with exposure to additives (smoke, salt, nitrites) and substances originating from preserved foods (nitrosamines) known to increase the risk for gastric cancer [11, 12].

In 1560, Jean Nicot (of nicotine fame) introduced tobacco to France, from where it spread throughout 
Europe. For the following three centuries it was smoked by relatively few, mostly in briar and clay pipes; the development of rolled cigarettes by Philip Morris of London and their subsequent industrial development by James Bonsack of Roanoke, Virginia in 1880, placed the smoking addiction within the reach of the masses. Free of the cumbersome requirements of the pipe, quick to light and smoke, a cigarette could be had in any place at any time. Within a few decades, more than half of the male population in much of Europe smoked regularly. The rates of lung and laryngeal cancer started increasing and peaked in the cohorts born in the first quarter of the 20th century [13]. Cigarette smoking, which significantly increases gastric cancer risk in $H$. pylori-infected subjects (then the overwhelming majority of the population), became the third factor to act synergistically with $H$. pylori and food preservation to promote gastric cancer $[14,15]$.

Just as these three gastric cancer-promoting factors surged in the 19th century, they began declining in the 20th century. Improved sanitary conditions in Europe and North America have decreased the transmission of $H$. pylori infection and widespread use of antibiotics has curtailed its prevalence. As a result, in most developed countries H. pylori now infects less than $20 \%$ of adults and $5 \%$ of children. Laws designed to reduce the content of dangerous chemicals in cured meats [16] and refrigeration transformed the smoking and salting of meats and fish from necessity to occasional delicacy. And a few decades after doctors paraded themselves as proud smokers of a particular brand of cigarettes named after an even-toed ungulate of the genus Camelus, the recognition that both first- and second-hand smoke cause lung cancer prompted successful anti-smoking campaigns and laws in the United States and later in Europe. In many countries these measures have effectively reduced the number of smokers from more than half to less than a quarter of the population $[17,18]$.

The relative influence of each of these factors on the rise and fall of gastric cancer is difficult to evaluate; since none is a sufficient cause of cancer, they must have acted synergistically, almost certainly in concert with other yet unknown factors. These known and unknown factors may also have contributed to forge the similar but delayed mortality patterns for gastric and duodenal ulcer; although both occur in a background of $H$. pylori-gastritis, historical time trends show a quarter century interval between cancer and ulcers. This enigma, highlighted by Sonnenberg [10], could be solved if and when more co-factors and their relative contributions to the development of cancer and ulcers were discovered and better understood. In view of the rapid decline of $H$. pylori infection and its associated conditions in the Western world, some answers might have to be sought in developing countries, where some of the events that shaped the European stomach in the last century may now be recapitulated, albeit at an accelerated pace. Even if the hypotheses generated by historical analysis of gastric cancer trends may ultimately remain untested, they might be adapted to investigate other diseases with yet unknown etiologies and equally intriguing time trends, such as inflammatory bowel disease. We will be waiting for Sonnenberg.

Conflict of interest The preparation of this manuscript was not supported by external funding. The author declares no conflict of interest relevant to this manuscript.

\section{References}

1. Susser M, Stein Z. Civilisation and peptic ulcer. Lancet. 1962;i:115-119.

2. Susser M, Stein Z. Commentary: civilization and peptic ulcer 40 years on. Int J Epidemiol. 2002;31:18-21.

3. Marshall BJ, Warren JR. Unidentified curved bacilli in the stomach of patients with gastritis and peptic ulceration. Lancet. 1984;i:1311-1315.

4. Sonnenberg A, Muller H, Pace F. Birth-cohort analysis of peptic ulcer mortality in Europe. J Chronic Dis. 1985;38:309-317.

5. Sonnenberg A. Occurrence of a cohort phenomenon in peptic ulcer mortality from Switzerland. Gastroenterology. 1984;86: 398-401.

6. Sonnenberg A, Muller H. Cohort and period effects in peptic ulcer mortality from Japan. J Chronic Dis. 1984;37:699-704.

7. Sonnenberg A, Fritsch A. Changing mortality of peptic ulcer disease in Germany. Gastroenterology. 1983;84:1553-1557.

8. Sonnenberg A. Temporal trends and geographical variations of peptic ulcer disease. Aliment Pharmacol Ther. 1995;9:3-12.

9. Sonnenberg A. The US temporal and geographic variations of diseases related to Helicobacter pylori. Am J Public Health. 1993;83:1006-1010.

10. Sonnenberg A. Time trends of mortality from gastric cancer in Europe. Dig Dis Sci. 2011. doi:10.1007/s10620-010-1553-2.

11. Joossens JV, Hill MJ, Elliott P, et al. Dietary salt, nitrate and stomach cancer mortality in 24 countries. European cancer prevention (ECP) and the INTERSALT cooperative research group. Int J Epidemiol. 1996;25:494-504.

12. Stillwell WG, Xu HX, Glogowski J, et al. Comparison of urinary nitrate, $\mathrm{N}$-nitrosoproline, 7-methylguanine and 3-methyladenine levels in a human population at risk for gastric cancer. IARC Sci Publ. 1991;105:83-87.

13. Bray FI, Weiderpass E. Lung cancer mortality trends in 36 European countries: secular trends and birth cohort patterns by sex and region 1970-2007. Int J Cancer. 2010;126:1454-1466.

14. Tredaniel J, Boffetta P, Buiatti E, et al. Tobacco smoking and gastric cancer: review and meta-analysis. Int J Cancer. 1997;72: $565-573$

15. You WC, Zhang L, Gail MH, et al. Gastric dysplasia and gastric cancer: Helicobacter pylori, serum vitamin $\mathrm{C}$, and other risk factors. J Natl Cancer Inst. 2000;92:1607-1612.

16. Paik DC, Saborio DV, Oropeza R, et al. The epidemiological enigma of gastric cancer rates in the US: was grandmother's sausage the cause? Int J Epidemiol. 2001;30:181-182.

17. Messer K, Trinidad DR, Al-Delaimy WK, et al. Smoking cessation rates in the United States: a comparison of young adult and older smokers. Am J Public Health. 2008;98:317-322.

18. Pierce JP. International comparisons of trends in cigarette smoking prevalence. Am J Public Health. 1989;79:152-157. 